\title{
Effect of supportive therapy on the incidence of post-partum depression
}

\author{
Mona Nongmeikapam ${ }^{1}$, Sruthi Talasila ${ }^{2 *}$, Mohan Reddy ${ }^{1}$, Sheela S. R. ${ }^{1}$ \\ ${ }^{1}$ Department of Psychiatry, ${ }^{2}$ Department of Obstetrics and Gynecology, SDUMC, Tamaka, Kolar, Karnataka, India
}

Received: 16 March 2018

Accepted: 23 March 2018

\section{*Correspondence:}

Dr. Sruthi Talasila,

E-mail: sruthitalasila99@gmail.com

Copyright: $\odot$ the author(s), publisher and licensee Medip Academy. This is an open-access article distributed under the terms of the Creative Commons Attribution Non-Commercial License, which permits unrestricted non-commercial use, distribution, and reproduction in any medium, provided the original work is properly cited.

\begin{abstract}
Background: Postpartum non-psychotic depression (PND) is the most common complication of childbirth with approximately $10-42 \%$ prevalence across the globe. Especially in rural south Indian population, fear of stigma, superstitions, poverty and poor medical access by the pregnant women leads to a large number of un-diagnosed and poorly treated cases of post-partum depression. Objective of study was to study the effect of Supportive therapy on the incidence of post-partum depression in women attending the Obstetrics Department of SDUMC, Kolar using the Edinburgh Depression Rating Scale and to compare the findings with that with a control population.

Methods: 200 ladies in their second trimester of pregnancy were taken up for the study; 100 out of these were psycho-educated about the risks and signs of Post-partum depression and subjected to supportive therapy sessions. On the 5th day after their delivery, they were assessed using the Edinburgh Postnatal Depression Scale (EPDS). The other 100 patients (control group) were directly interviewed using the EPDS on day 5 post-partum.

Results: The overall depression among treatment group $(17 \%)$ is significantly lower when compared to the control group (41\%). The Mean depression score of treatment group (5.41) was significantly lower when compared to control group (8.65) which is statistically significant. Amongst the treatment group, marital status, occupation, education and bad obstetric history were found to have a significant influence on depression.

Conclusions: The overall depression among treatment group $(17 \%)$ is significantly lower when compared to the control group (41\%). The Mean depression score of treatment group (5.41) was significantly lower when compared to control group (8.65) which is statistically significant. Amongst the treatment group, marital status, occupation, education and bad obstetric history were found to have a significant influence on depression.
\end{abstract}

Keywords: Post-partum depression, Perinatal metal health, Supportive therapy

\section{INTRODUCTION}

Postpartum non-psychotic depression (PND) is the most common complication of childbirth with approximately $10-42 \%$ prevalence across the globe. ${ }^{1-4}$ PND is characterised by depressive episodes with anhedonia, insomnia and increased fatigue experienced by mothers up to 6 weeks post-partum ${ }^{1}$. Multifactorial aetiology namely demographic, economic, psychosocial, obstetric and medical risk have been cited. Factors like birth of girl child, traditional rituals, financial burden, domestic violence, lack of education, employment or social support and obstetric and medical complications have be named as major risk factors in South East Asian countries. ${ }^{2-6}$ Especially in rural south Indian population, fear of stigma, superstitions and sheer poverty leads to a large number of un-diagnosed and poorly treated cases of postpartum depression. PND and its risk factors have been explored by many authors in Indian setting. ${ }^{2-4}$ Several studies have explored various pharmacologic as well as psychosocial interventions to prevent and treat PND. ${ }^{7-15}$ Scant research has been conducted so far in local study setting especially with non-pharmacological interventions. On the other hand there are several factors 
limiting the use of pharmacologic methods in the new mothers including fear of exposure to the infant through breast milk, metabolic changes and various other concerns. $^{8}$ There is also the harsh reality that $34-65 \%$ mothers avail no ante-natal check-ups in many parts of our country and as less as only $35 \%$ avail hospital care for child-birth. ${ }^{12}$ Hence, in view of paucity of research among rural mothers in local setting, the limited antenatal facilities and the benefit of ante-partum intervention on the outcome of PND, this study aimed to elicit the effect of supportive therapy and psycho-education on the incidence and its socio-demographic correlates sociodemographic, obstetric and pregnancy outcome predictors of PND among postnatal women in rural part of Kolar district, Karnataka state, India and compare the findings with that of a control population.

\section{METHODS}

This study was conducted in Obstetric clinic of the Department of Obstetrics and Gynecology of Sri Devraj Urs Medical College situated in rural part of Kolar district, Karnataka state, India from June to November 2015. The hospital caters to the need of nearby villages and talukas and linked with many government health programmes for the benefit of rural poor.

\section{Inclusion criteria}

All patients in their $2^{\text {nd }}$ trimester of pregnancy attending the Obstetrics Department of SDUMC, Kolar.

\section{Exclusion criteria}

- Any anticipated obstetric complications or frank psychiatric history or on psychotropic medications or mental retardation or cognitive impairment

- Unwilling to participate in the study or attend at least 5 sessions of supportive therapy sessions.

Patients in their $2^{\text {nd }}$ attending the Obstetric department of SDUMC, Kolar. Total number of study subjects were 100 cases and 100 controls.

Purposive sampling method was used for sample selection. Systematic random sampling method for sample selection was employed. The sample size was estimated based anticipated $31.4 \%$ prevalence of postpartum depression from a previous study and expecting a difference of $55 \%$ reduction in the prevalence among controls $(17.2 \%)$, with $95 \%$ confidence interval and to detect a difference of 17.2 the sample size estimated to be 92 per group. ${ }^{2}$ Expecting a non-response rate of $10 \%$ the final sample size calculated per group was 100. A similar number of closely matched control subjects were taken.

Study tool was Edinburgh Depression Rating scale (EPDS). Design of the study was Descriptive Interventional type.
For the purpose of the present study, 100 ante-natal patients in their $2^{\text {nd }}$ trimesters were taken after obtaining their duly signed informed consents. Information related to their socio-demographic characteristics, detailed account of their menstrual and obstetric history, including bad obstetric history, past and present medical illnesses, family details and psychosocial stressor were recorded in a specially pre-designed proforma. Detailed psychoeducation about post-partum depression, its prevalence and presentation explained to them and doubts if any were clarified. They were made to undergo Supportive Psychotherapy throughout their antenatal period in the form of 30-minute therapy sessions conducted fortnightly. Each patient had to undergo a minimum of 5 such sessions. Following their delivery on the $5^{\text {th }}$ day post-partum, the Edinburgh postnatal depression rating scale was administered and scores were recorded.

For the 100 controls, they were subjected to their normal ANC evaluation monthly once in their second trimester and once every fortnight in their third trimester without any psychological intervention. On Day 5 post-partum, they too underwent evaluation for post-partum depression with the EPDS.

\section{Supportive psychotherapy}

Supportive therapy aims to improve, reinforce, or sustain a patient's physiological well-being or psychological selfesteem and self-reliance. ${ }^{16}$ For the purpose of our study, Supportive therapy was administered in the form of 30minute sessions conducted by a trained Psychiatrist or a Psychologist following the patient's monthly ANC check-ups at the Department of Obstetrics. Each case had to attend a minimum of 5 such sessions. Given the patients' state of being and cited difficulty in frequently attending Psychotherapy sessions, the focus was more on a now-and here approach, with the sessions aiming at educating the patient and her family, improving coping and problem-solving skills, allaying mood symptoms and raising her self-esteem.

\section{Edinburgh postnatal depression scale (EPDS)}

EPDS is one of the most widely used self-report instrument used to screen Depression in post-natal and ante-natal period. ${ }^{17-19}$ It is a 10 item self-reported scale based on 1 week recall, designed to screen PND in the community. Each item is rated from 0 to 3 , yielding a total score of $0-30$. Seven of its items are reversescored. ${ }^{19}$ In India, the Kannada (local language) version of EPDS has been validated to detect antenatal depression, and found to have a sensitivity of $100 \%$ and specificity of $84.9 \%$, at a cut-off score of $\geq 10 .{ }^{18}$ For this study, a cut-off score of $\geq 10$ on Kannada version of EPDS was used to diagnose PND. It was pre tested by the authors on 10 postnatal mothers to ensure that questions were easily understood by mothers and responses were correctly interpreted by the author. Woman with EPDS 
score of $\geq 13$ was taken up for further Psychiatric evaluation.

\section{Statistical analysis}

The collected data was coded and analysed using SPSS 22 software. Mean, standard deviation and confidence interval have been used to present all the quantitative measures. The mean depression scores of study group was compared using Independent student $t$ test and significance of difference in proportions and the association was done by Chi-square test. $\mathrm{P}$ value $\leq 0.05$ was considered as statistically significant.

\section{RESULTS}

200 patients satisfying the inclusion and exclusion criteria were taken up for the study during their post-natal visits during the study period, 100 of whom who had received intervention during their antenatal visits.

Table 1: Comparison of mean depression scores of treatment versus control groups.

\begin{tabular}{|llllll|}
\hline Group & N & Minimum & Maximum & Mean & Std. Deviation \\
Treatment group & 100 & 0 & 25 & 5.41 & 4.506 \\
\hline Control group & 100 & 0 & 21 & 8.65 & 5.802 \\
\hline
\end{tabular}

Table 2: In correlation to mean and standard deviation.

\begin{tabular}{|llllll|}
\hline EDPS & $\mathbf{N}$ & Minimum & Maximum & Mean & Std. Deviation \\
\hline 0 to 9 & 142 & 0 & 9 & 4.16 & 2.926 \\
10 to 12 & 23 & 10 & 12 & 10.91 & 0.848 \\
\hline$>13$ & 35 & 13 & 25 & 16.11 & 2.665 \\
\hline
\end{tabular}

Table 3: Comparing the treatment and control group findings.

\begin{tabular}{|c|c|c|c|c|}
\hline $\begin{array}{l}\text { EDPS } \\
\text { scores }\end{array}$ & $\begin{array}{l}\text { Treatment } \\
\text { group }\end{array}$ & $\begin{array}{l}\text { Control } \\
\text { group }\end{array}$ & Total & $\begin{array}{l}\text { P- } \\
\text { value }\end{array}$ \\
\hline 0 to 9 & 83 & 59 & 142 & \\
\hline 10 to 12 & 10 & 13 & 23 & 0.001 \\
\hline$>13$ & 7 & 28 & 35 & \\
\hline Total & 100 & 100 & 200 & \\
\hline
\end{tabular}

The overall depression among the treatment group (17\%) is significantly lower when compared to the control group $(41 \%)(\mathrm{p}=0.001)$.
The Mean depression score of treatment group (5.41) was significantly lower when compared to control group (8.65) which is statistically significant.

Table 4: Independent $t$ test.

\begin{tabular}{|c|c|c|c|c|c|}
\hline & Group & $\mathbf{N}$ & Mean & $\begin{array}{l}\text { Std. } \\
\text { deviation }\end{array}$ & $\begin{array}{l}P \\
\text { value }\end{array}$ \\
\hline \multirow{2}{*}{ EPDS } & $\begin{array}{l}\text { Treatment } \\
\text { group }\end{array}$ & 100 & 5.41 & 4.506 & \multirow{2}{*}{0.001} \\
\hline & $\begin{array}{l}\text { Control } \\
\text { group }\end{array}$ & 100 & 8.65 & 5.802 & \\
\hline
\end{tabular}

Table 5: Socio-demographic characteristics of cases and controls.

\begin{tabular}{|c|c|c|c|c|c|c|}
\hline \multirow{2}{*}{ Characteristic } & \multicolumn{3}{|l|}{ Cases } & \multicolumn{3}{|l|}{ Control } \\
\hline & EPDS $<10$ & EPDS $>10$ & $P$ value & EPDS $<10$ & EPDS $>10$ & $P$ value \\
\hline Age (in years) & 87 & 13 & 0.958 & 64 & 36 & 0.213 \\
\hline Married life (in years) & 87 & 13 & 0.467 & 64 & 36 & 0.030 \\
\hline Marital status & 87 & 13 & 0.009 & 98 & 2 & 0.542 \\
\hline Domicile & 87 & 13 & 0.542 & 64 & 36 & 0.040 \\
\hline Income & 87 & 13 & 0.674 & 64 & 36 & 0.960 \\
\hline Occupation & 87 & 13 & 0.001 & 98 & 2 & 0.605 \\
\hline Religion & 87 & 13 & 0.807 & 64 & 36 & 0.220 \\
\hline Education & 87 & 13 & 0.028 & 98 & 2 & 0.303 \\
\hline Family type & 87 & 13 & 0.845 & 64 & 64 & 0.171 \\
\hline
\end{tabular}


Table 6: Life events and family factors in cases and control.

\begin{tabular}{|lllllll|}
\hline Event/ factor & Cases & & & Control & \\
\hline Consanguinity & EPDS $<\mathbf{1 0}$ & EPDS $>\mathbf{1 0}$ & P value & EPDS $<\mathbf{1 0}$ & EPDS $>\mathbf{1 0}$ & P value \\
\hline Physical illness & 87 & 13 & 0.386 & 64 & 36 & 0.837 \\
\hline Substance use & 87 & 13 & 0.635 & 64 & 36 & 0.992 \\
\hline Miscellaneous factors & 87 & 13 & 0.509 & 64 & 36 & 0.187 \\
\hline Psychosocial stressor & 87 & 13 & 0.698 & 64 & 36 & 0.251 \\
\hline
\end{tabular}

Table 7: Obstetric history of cases and control.

\begin{tabular}{|lllllll|}
\hline History & Cases & & & Control & & \\
\hline Period of gestation & EPS $<\mathbf{1 0}$ & EPDS $>\mathbf{1 0}$ & P value & EPDS $<\mathbf{1 0}$ & EPDS $>\mathbf{1 0}$ & P value \\
\hline Gravid & 87 & 13 & 0.294 & 64 & 36 & 0.007 \\
\hline Parity & 87 & 13 & 0.890 & 87 & 13 & 0.768 \\
\hline Abortion & 87 & 13 & 0.706 & 98 & 2 & 0.902 \\
\hline Dead & 87 & 13 & 0.031 & 98 & 2 & 0.029 \\
\hline Living issues & 87 & 13 & 0.674 & 64 & 36 & 0.552 \\
\hline Mode of delivery & 87 & 13 & 0.522 & 64 & 36 & 0.18 \\
\hline Status & 87 & 12 & 0.879 & 64 & 36 & 0.811 \\
\hline & 87 & 12 & 0.042 & 64 & 36 & 0.668 \\
\hline
\end{tabular}

The lower mean scores in treatment group can be attributed to Supportive therapy and psycho-education given. Among the cases, occupational status proved to have a significant influence on depression. The difference in proportion of severe depression between various occupational groups was found to be statistically significant.

Among the controls, only $2 \%$ of the total who are housewives had severe depression. Educational status of the cases also had a significant influence on the outcome. The difference in proportion of severe depression among the various educational groups was statistically significant. In the control group, only $2 \%$ (who had primary education and graduates) had severe depression. Bad obstetric history in the form of abortions significantly influenced the EPDS score. The difference in proportion of severe depression among the patients with bad obstetric history was statistically significant. A similar trend was observed in the control group as well.

\section{DISCUSSION}

\section{Main findings}

A large portion of the control group who came for follow-up in their fourth to tenth week of postpartum was found to have post-partum depression. The overall depression among treatment group (17\%) is significantly lower when compared to the control group (41\%). This value is comparable with other studies that found a prevalence (26.3-31.4\%) using the EPDS scale in hospital as well as community-based settings., ${ }^{2,3}$ The Mean depression score of treatment group (5.41) was significantly lower when compared to control group (8.65) which is statistically significant. A similar trend was noted in a Turkish semi-urban population where mean EPDS score of 258 pregnant women was found to be $9.5( \pm 5.2)$ without any intervention. ${ }^{5}$ This finding indicates the effectiveness of the interventional methods in the form of educating the patients and supportive psychotherapy during the antenatal check-ups. Similar trends have been reflected in studies adopting nonpharmacological intervention techniques ranging from cognitive behavioural therapy (CBT), psychological debriefing and peer support. ${ }^{11-15}$

One study revealed that Depression scores with EPDS scale reduced in the most symptomatic women steadily by over $50 \%$ over the total time course of 4 months of follow-up but there were no differences in improvement between the intervention (receiving CBT) and control groups(educated with information booklets on PND), indicating that even the simplest form of psychoeducation may even prove useful in prevention of PND in literate populations. ${ }^{11}$ Amongst the treatment group, marital status, occupation, education and bad obstetric history were found to have a significant influence on depression. Maternal age, gender of the child or of previous children, adverse life events and perceived social and environmental support have been found to show similar trend in previous studies. ${ }^{2-6}$

The difference in proportion of severe depression between the various sub-groups was found to be statistically significant. This finding bears serious implications as Depression is heralded as the leading cause of disability worldwide. It negative affect the 
children born to these mothers owing to impaired motherinfant bonding, rejection or even abusive behavior in some unfortunate cases. ${ }^{7}$

\section{Interpretations}

In rural settings like ours where pregnant mothers have poor access to medical care and rarely come for ANC check, screening them for post-partum depression and educating them while they come for their ANC check-ups is one fool-proof way to detect ante-natal and post-natal depression.

Nonpharmacological preventive methods will go a long way in preventing PND as mothers are reluctant to receive pharmacological interventions due to fear of sideeffects to the child or self and also the associated stigma. We also observed that education and employment in mothers act as a protective factor against post-natal depression.

\section{Limitations of study were:}

- A relatively a small sample was studied in our study. $34 \%$ of the mothers have no access to a single ANC check-up.12 Therefore results would apply to women attending hospitals/clinics and cannot comment on those who do not receive postnatal care. Nonetheless, the present study gives valuable hints to practicing obstetricians and primary care physicians in resource constrained rural India for early identification and apt preventive intervention for women at risk of PND.

- Women with abortion or stillbirth did not come for follow up during the study period. Therefore we could not study their association with PND.

- EPDS is a screening tool for PND and not confirmatory.

- Follow-up is a limitation as the women tend to discontinue postnatal check-ups shortly following the birth of their child.

\section{CONCLUSION}

Antenatl vigilance including educating pregnant women and their families about postpartum depression and subjecting them to supportive therapy sessions during their ANC visits helps in curbing the incidence of postnatal depression.

\section{ACKNOWLEDGMENTS}

Authors would like to thank Dr. Ravi Shankar for statistical support and other valuable inputs.

Funding: Indian Council Medical Research (ICMR) and SDUAHER

Conflict of interest: None declared

Ethical approval: The study was approved by the Institutional Ethics Committee

\section{REFERENCES}

1. World Health Organization. International Statistical Classification of Diseases and Related Health Problems 10th Revision (ICD-10). Available:http://apps.who.int/classifications/apps/icd /icd10online/ Published 2007.

2. Shivalli S, Gururaj N. Postnatal Depression among Rural Women in South India: Do SocioDemographic, Obstetric and Pregnancy Outcome Have a Role to Play? PLOS ONE. 2015;10(4):e0122079.

3. Savarimuthu R, Ezhilarasu P, Charles H, Antonisamy B, Kurian S, Jacob K. Post-partum depression in the community: a qualitative study from rural South India. Int J Soc Psych. 2010;56:94102.

4. Chandran M, Tharyan P, Muliyil J. Post-partum depression in a cohort of women from a rural area of Tamil Nadu, India: Incidence and risk factors. Br J Psych. 2002;181(6):499-504.

5. Bennett HA, Einarson A, Taddio A, Koren G, Einarson TR. Prevalence of depression during pregnancy systematic review. Obstet Gynecol. 2004;103:698-709.

6. Golbasi Z, Kelleci M, Kisacik G, Cetin A. Prevalence and correlates of depression in pregnancy among Turkish women. Matern Child Health J 2010;14:485-91.

7. Sockol L, Epperson C, Barber J. Preventing postpartum depression: A meta-analytic review. Clin Psychol Rev. 2013;33(8):1205-17.

8. Fitelson E, Kim S, Baker A. Treatment of postpartum depression: clinical, psychological and pharmacological options. Int $\mathbf{J}$ Womens Health. 2011;3:1-14.

9. Chandra P. Post-partum psychiatric care in India: the need for integration and innovation. World Psychiatry. 2004 Jun;3(2):99-100

10. Stamp G, Williams A, Crowther C. Evaluation of antenatal and postnatal support to overcome postnatal depression: a randomized, controlled trial. Birth. 1995;22(3):138-143.

11. Austin M, Frilingos M, Lumley J, Hadzi-Pavlovic D, Roncolato W, Acland S et al. Brief antenatal cognitive behaviour therapy group intervention for the prevention of postnatal depression and anxiety: A randomised controlled trial. J Affect Dis. 2008;105(1-3):35-44.

12. Boath E, Bradley E, Henshaw C. The prevention of postnatal depression: A narrative systematic review. J Psychosomat Obstet Gynecol. 2005;26(3):185-92.

13. Dennis C. Preventing Postpartum Depression Part II: A Critical Review of Nonbiological Interventions. The Canadian Journal of Psychiatry. 2004;49(8):52638.

14. Dennis C. Psychosocial and psychological interventions for prevention of postnatal depression: systematic review. BMJ. 2005;331(7507):15-0. 
15. Dennis C, Hodnett E, Kenton L, Weston J, Zupancic J, Stewart D et al. Effect of peer support on prevention of postnatal depression among high risk women: multisite randomised controlled trial. BMJ. 2009;338(jan15 2):a3064.

16. Misch DA. Basic Strategies of Dynamic Supportive Therapy. J Psychother Pract Res. 2000;9(4):173-89.

17. Cox J, Holden J, Sagovsky R. Detection of postnatal depression. Development of the 10-item Edinburgh Postnatal Depression Scale. Br J Psych. 1987;150(6):782-6.

18. Fernandes M, Srinivasan K, Stein A, Menezes G, Sumithra R, Ramchandani P. Assessing prenatal depression in the rural developing world: a comparison of two screening measures. Arch Women's Mental Health. 2010;14(3):209-216.

19. Matthey S, Barnett B, White T, Cox J, Holden J. The Edinburgh postnatal depression scale. Br J Psych. 2003;182(4):368.

Cite this article as: Nongmeikapam M, Talasila S, Reddy M, Sheela SR. Effect of supportive therapy on the incidence of post-partum depression. Int J Reprod Contracept Obstet Gynecol 2018;7:2106-11. 